\title{
Comparison of Methods for Quantifying Dental Wear Caused by Erosion and Abrasion
}

\author{
VANARA F. PASSOS, MARY A.S. MELO, ANDRÉA ARAÚJO VASCONCELLOS, \\ LIDIANY K.A. RODRIGUES, AND SÉRGIO L. SANTIAGO* \\ Faculty of Pharmacy, Dentistry and Nursing, Federal University of Ceará, Fortaleza, Ceará, Brazil
}

\begin{abstract}
KEY WORDS erosion; abrasion; profilometry; enamel; dentin; hardness
\end{abstract}
\begin{abstract}
Various methods have been applied to evaluate the effect of erosion and abrasion. So, the aim of this study was to check the applicability of stylus profilometry (SP), surface hardness (SH) and focus-variation 3D microscopy (FVM) to the analysis of human enamel and dentin subjected to erosion/abrasion. The samples were randomly allocated into four groups $(n=10)$ : G1-enamel/erosion, G2-enamel/erosion plus abrasion, G3-dentin/erosion, and G4-dentin/erosion plus abrasion. The specimens were selected by their surface hardness, and they were subjected to cycles of demineralization (Coca-Cola ${ }^{\mathbb{B}}-60 \mathrm{~s}$ ) and remineralization (artificial saliva-60 min). For groups G2 and G4, the remineralization procedures were followed by toothbrushing (150 strokes). The above cycle was repeated $3 \times$ /day during 5 days. The samples were assessed using $\mathrm{SH}, \mathrm{SP}$, and FVM. For each substrate, the groups were compared using an unpaired t-test, and Pearson correlation coefficients were calculated $(\alpha=5 \%)$. For enamel, both profilometry technique showed greater surface loss when the erosion and abrasion processes were combined $(P<0.05)$. The correlation analysis did not reveal any relationships among SH, SP, and FVM to G2 and G4. There were significant correlation coefficients $(-0.70$ and -0.67$)$ for the comparisons between the FVM and SH methods in enamel and dentin, respectively, in G1 and G3. Choosing the ideal technique for the analysis of erosion depends on the type of dental substrate. SP was not sufficiently sensitive to measure the effects on dentin of erosion or erosion/abrasion. However, SP, FVM and SH were adequate for the detection of tissue loss and demineralization in enamel. Microsc. Res. Tech. 76:178-183, 2013. @ 2012 Wiley Periodicals, Inc.
\end{abstract}

\section{INTRODUCTION}

Dental erosion has been highlighted by the recent emphasis in dentistry on considering and understanding the causes of alterations in dental hard tissues and the effects of acidic soft drinks on these tissues (Serra et al., 2009). The strong interest in this subject is indicated by the large numbers of in vitro and in situ studies published on it (Ganss et al., 2000; Hannig et al., 2008; Lussi et al., 2000; Passos et al., 2010; Ren et al., 2009a,b; Schlueter et al., 2009a,b).

The precise characterization and measurement of hard tissue is of prime importance in much dental research because the detrimental effects of dental erosion are strongly influenced by interactions with abrasive forces (Wiegand et al., 2007). This process is especially important for surfaces characterized by various diversified microstructures with a number of irregular peaks and valleys that cannot be easily defined.

The search for the optimal methodology to analyze and describe surface topographies, as well as measure the amount of hard tissue loss, has gained considerable support in the literature (Attin, 2006; Heurich et al., 2010). The literature contains many well-known methods for the characterization and quantification of dental erosion. Among these techniques, the hardness tester (Hannig et al., 2008; Lussi et al., 2000; Passos et al., 2010; Saghiri et al., 2009; Wiegand et al., 2007), microradiography (Ganss et al., 2005, 2009; Lo et al., 2010), energy-dispersive X-ray fluorescence (de
Carvalho Filho et al., 2011) and profilometry (Chuenarrom and Benjakul, 2008; Ganss et al., 2000, 2005, 2009; Hannig et al., 2008; Hjortsjo et al., 2010; Ren et al., 2009a; Schlueter et al., 2009a,b) have been highlighted.

The determination of surface hardness has been a common means of quantifying erosive effects; for example, the Knoop hardness test measures alterations in the superficial layer based on the geometry of a diamond indenter (Attin, 2006; Lussi et al., 2000). Due the limited capacity of hardness measurement after an aggressive erosive challenge and the destruction of samples and time consuming by microradiography (Lo et al., 2010), the most commonly reported method in dental research is profilometry (Fujii et al., 2011; Ganss et al., 2009; Heurich et al., 2010). Stylus profilometry is an older, more established technique that involves traversing the tooth surface using a contact tip. The vertical motion of the contact tip is transformed into an analog/digital signal that indicates the depth of substrate loss, ranging from 2 to $250 \mu \mathrm{m}$. However, there is a risk of the diamond tip damaging the specimen (Field et al., 2010).

\footnotetext{
*Correspondence to: Sérgio L. Santiago, Faculty of Pharmacy, Dentistry and Nursing, Federal University of Ceará Alexandre Baraúna 949, $3^{\circ}$ Andar Rodolfo Teófilo - Zip Code: 60430-160 Fortaleza-CE, Brazil.

E-mail: sergiosantiago@ufc.br

Received 18 March 2012; accepted in revised form 10 October 2012

DOI 10.1002/jemt.22150

Published online 6 November 2012 in Wiley Online Library (wileyonlinelibrary.com).
} 
Optical profilometry can overcome many of the drawbacks of contact profilometry because it does not involve direct contact with the surface and because its use in recent years to evaluate dental erosion has produced consistently satisfactory results (Ganss et al., 2009).

Another methodology with great potential in dental studies that involve a quantitative evaluation of surface topography is focus-variation 3D microscopy (FVM). This technique combines the small depth of focus of an optical system with vertical scanning to provide topographical and color information from the variation of focus (Ren et al., 2009a). FVM, is a noncontact method, utilizes optical imaging; it does not cause any damage to the surface of the specimen (Fujii et al., 2011). Ren et al. (2009a,b) have reported that FVM is an adequate tool for evaluating dental erosion.

A comparison of FVM and stylus profilometry was expected to be instructive because these techniques have different measurement principles, which can cause different results, leading to inconsistent conclusions. The objective of this study was therefore to investigate the profile outcomes of two profilometric methods and hardness analysis in enamel and dentin substrates that had undergone erosive or erosive plus abrasive challenges.

\section{MATERIALS AND METHODS Experimental Design}

This study employed a completely randomized, single-blind experimental design with 10 experimental units per treatment. It evaluated human enamel and root dentin that had been subjected to two types of challenge: erosive and erosive plus abrasive. The response variables were wear depth (expressed in micrometers) and the percentage of surface hardness loss.

\section{Preparation of Dental Samples}

Sound third molars were used in this in vitro study following approval from the Research and Ethics Committee of the Federal University of Ceará (protocol $\# 272 / 2009)$. The teeth were refrigerated at $4^{\circ} \mathrm{C}$ in a $0.01 \%(\mathrm{w} / \mathrm{v})$ thymol solution until use. Slabs $(4 \mathrm{~mm} \times 4$ $\mathrm{mm} \times 2 \mathrm{~mm}$ ) of dentin and enamel were obtained from these teeth using a water-cooled diamond saw and a cutting machine (IsoMet Low-Speed Saw, Buehler, Lake Bluff, IL). The slabs were embedded in acrylic resin cylinders to facilitate handling (Arotec SA Ind. e Com, Cotia, SP, Brazil) and serially polished with 400-, 600- and 1200-grit $\mathrm{Al}_{2} \mathrm{O}_{3}$ grinding papers under water refrigeration, followed by the application of a $1-\mu \mathrm{m}$ diamond paste on a rotating polishing machine (Arotec SA Ind. e Com). Subsequently, the slabs were sonicated for $10 \mathrm{~min}$ in distilled water, identified by number and stored under refrigeration.

Each slab was then divided into two halves, with one half of each specimen serving as the test surface. The other half was covered with a dark-colored acid-resistant nail varnish (Colorama, CEIL Coml. Exp. Ind., São Paulo, SP, Brazil) and did not undergo any further treatments. The surface hardness was determined by performing five indentations for $5 \mathrm{~s}$ with a Knoop diamond (FM 100, Future Tech, Tokyo, Japan). A 50-g load was used for enamel, and a 25-g load was used for dentin. The indentations were performed in the center of the slab surface for selection and randomized distribution purposes. Twenty dentin and 20 enamel slabs with hardness values between $43-52$ and 315-385 Knoop hardness numbers $(\mathrm{KHN})$, respectively, were selected. A computer-generated randomization list was used to randomly assign these specimens into the following groups $(n=10)$ : G1-enamel/erosion, G2enamel/erosion plus abrasion, G3-dentin/erosion, and G4-dentin/erosion plus abrasion.

\section{Erosion-Abrasion Cycling Model}

Demineralization was performed by immersing each slab in $5 \mathrm{~mL}$ of a carbonated soft drink (Coca-Cola, the Coca-Cola Co., Maracanaú, CE, Brazil) and statically incubating it for $1 \mathrm{~min}$. Next, the slabs were washed with deionized water for $10 \mathrm{~s}$ and immersed in $70 \mathrm{~mL}$ of artificial saliva $\left(1.45 \mathrm{mM} \mathrm{Ca}, 5.4 \mathrm{mM} \mathrm{PO}_{4}, 0.1 \mathrm{M}\right.$ Tris buffer, $2.2 \mathrm{~g} / \mathrm{L}$ porcine gastric mucin, $\mathrm{pH}$ 7.0) for 60 min using a magnetic stirrer $(100 \mathrm{rpm})$.

Subsequently, the slabs that had been assigned to erosive plus abrasive regimens were subjected to 150 cycles of the abrasive challenge in an automatic brushing machine (MSEt, 1500 W, Marcelo Nucci ME, São Carlos, SP, Brazil) under a $200-\mathrm{g}$ load at 4.5 movements per second and $37 \pm 0.5^{\circ} \mathrm{C}$. During the toothbrushing, the samples were bathed by a 1:3 w/w slurry of commercially available fluoride toothpaste (Colgate Total $^{\circledR} 12$ Clean Mint, containing 1450 ppm F as NaF; Colgate-Palmolive Ltd, São Paulo, SP, Brazil) and artificial saliva.

The cycling was repeated three times per day for five days at room temperature. All of the samples were stored overnight in artificial saliva at $37^{\circ} \mathrm{C}$. Following the treatments, the acid-resistant varnish was removed, and the surface wear was analyzed using a hardness measurement method and two profilometric methods.

\section{Analysis of Percentage of Surface Hardness Loss (\%SHL)}

The percentage of surface hardness loss was measured using a Knoop diamond (FM 100, Future Tech, Tokyo, Japan). Five 5-sec indentations were performed for enamel (50-g load) and dentin (25-g load) in the center of the slab surface, and an average per group was calculated. Indentations were made $100 \mu \mathrm{m}$ apart on each specimen, with five on sound surface hardness $(\mathrm{SH})$ and five following the erosive stage $\left(\mathrm{SH}_{1}\right)$. These measurements were used to calculate the percentage of surface hardness change $(\% \mathrm{SHL})$ as $\% \mathrm{SHL}=\left(\mathrm{SH}-\mathrm{SH}_{1}\right)$ $\times 100 / \mathrm{SH}$.

\section{Stylus Profilometry (SP)}

The specimens were allowed to dry for $10 \mathrm{~min}$ before analysis in order to reduce the possible interference caused by the shrinkage of dentin organic content. The tooth wear of each test surface was determined in relation to the reference surface (covered by nail varnish) using the Hommel Tester T 1000 profilometer (HOMMELWERKE GmbH, Alte Tuttinger Strebe 20. D-7730. VS- Schwenningen). At intervals of $100 \mu \mathrm{m}$, five profile traces (1.5 mm in length) were recorded on each specimen. These profilometric traces were produced by moving the stylus from the reference surface to the test 
TABLE I. Means and standard deviations (SD) of wear and percentages of superficial hardness loss

\begin{tabular}{|c|c|c|c|c|}
\hline \multicolumn{5}{|c|}{ Analysis } \\
\hline \multirow[b]{2}{*}{ Substrate } & \multirow[b]{2}{*}{ Challenges } & \multicolumn{2}{|c|}{ Wear $(\mu \mathrm{m}) \pm \mathrm{SD}$} & \multirow{2}{*}{$\frac{\% \mathrm{SHL} \pm \mathrm{SD}}{\mathrm{SH}}$} \\
\hline & & $\overline{\text { FVM }}$ & SP & \\
\hline $\begin{array}{l}\text { Enamel } \\
\text { Dentin }\end{array}$ & $\begin{array}{l}\text { Erosion } \\
\text { Erosion }+ \text { abrasion } \\
\text { Erosion } \\
\text { Erosion }+ \text { abrasion }\end{array}$ & $\begin{array}{l}0.89(0.42)^{\mathrm{a}} \\
2.53(0.74)^{\mathrm{b}} \\
3.85(0.94)^{\mathrm{A}} \\
4.44(1.06)^{\mathrm{A}}\end{array}$ & $\begin{array}{l}0.36(0.10)^{\mathrm{a}} \\
0.78(0.09)^{\mathrm{b}} \\
1.36(0.32)^{\mathrm{A}} \\
1.22(0.30)^{\mathrm{A}}\end{array}$ & $\begin{array}{c}53.39(5.58)^{\mathrm{a}} \\
24.93(11.57)^{\mathrm{b}} \\
-21.25(12.31)^{\mathrm{A}} \\
-16.25(29.13)^{\mathrm{A}}\end{array}$ \\
\hline
\end{tabular}

Different lowercase letters denote a significant difference between type of challenges to the enamel, and similar capital letters imply no significant differences between erosion and erosion plus abrasion challenges on dentin when unpaired $t$ test was used.

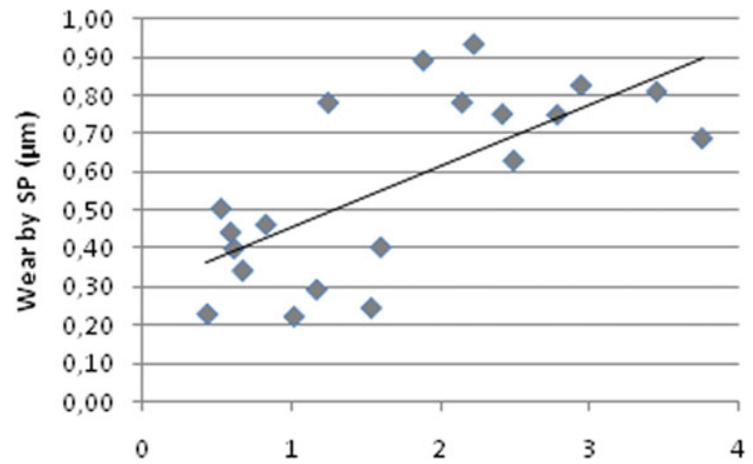

a

Wear by FVM ( $\mu \mathrm{m})$

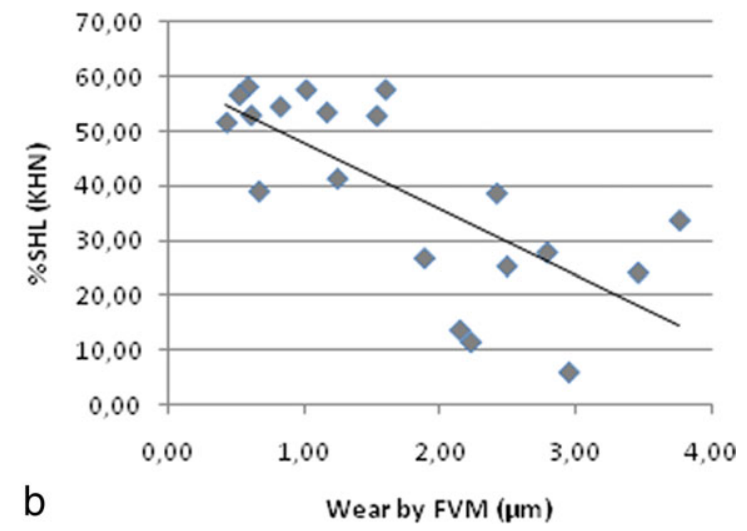

Fig. 1. Correlations between surface wear on an enamel substrate for SP and FVM (a) and for FVM and \% SHL (b). [Color figure can be viewed in the online issue, which is available at wileyonlinelibrary. com.]

surface. The mean of the values obtained from five traces was calculated for each sample.

\section{Surface 3D Topography Evaluation}

Topographic images of the eroded surfaces of the teeth were created using 3D focus-variation scanning microscopy, a kind of optical profilometry, at magnifications of approximately $200 \times$ (Alicona Imaging, Grambach/Graz, Austria). The unfiltered direct profiles of the measurement surfaces and 3D images of enamel and dentin were captured, and the average maximum profile heights $(\mathrm{Pz}$, representing the average depth of erosion) of the sampled profiles across the measurement length were recorded. The mean of the values obtained from five traces was calculated for each sample.

\section{Statistical Analysis}

Initially, the assumptions of equality of variances (Levene's test) and a normal distribution of errors (the Shapiro-Wilk test) were verified. For each substrate, the erosion and erosion plus abrasion groups were compared using an unpaired $t$-test. The linear dependence between the measurements obtained with the stylus profilometry, FVM and percentage of hardness loss methods was determined using Pearson's correlation test (the Pearson product-moment correlation coefficient $=r$ ) to determine the degree of similarity between any two data sets. The statistical analyses were performed using SAS $^{\mathbb{R}}$ statistical software (SAS
Institute, Cary, NC). The level of significance was set at $5 \%$.

\section{RESULTS}

The mean percentages of the changes in superficial hardness and the wear data obtained from the 3D scanning microscopy and the mechanical stylus are presented in Table 1. For enamel substrate, there were statistically differences for the erosion plus abrasion group compared with the erosion-only, according to the FVM, SP and \%SHL analyses $(P<0.0001)$. Otherwise, there were no significant differences between the dentin erosion and erosion plus abrasion groups $(P=0.205$ for 3D scanning microscopy, $P=0.301$ for stylus profilometry and $P=0.6261$ for the percentage of hardness loss).

In regard to Pearson correlation results, when data were analyzed considering solely slabs subjected only to erosion, the enamel samples displayed an inverse correlation between \%SHL and FVM $(r=-0.70, P=0.023)$. In contrast, enamel samples subjected to erosion plus abrasion showed no significant correlations using any method of evaluation. However, when all enamel substrate data were analyzed no mattering that slabs were subjected to erosion or erosion plus abrasion a positive correlation between SP and FVM $(r=0.70, P=0.0005)$ (Fig. 1a) and an inverse correlation between \%SHL and FVM $(r=-0.74, P=0.0002)$ (Fig. 1b) were observed.

The dentin slabs were the most susceptible to acid dissolution and exhibited a wide range of erosion depths $(1.36-3.85 \mu \mathrm{m})$ when the SP and FVM techniques were 


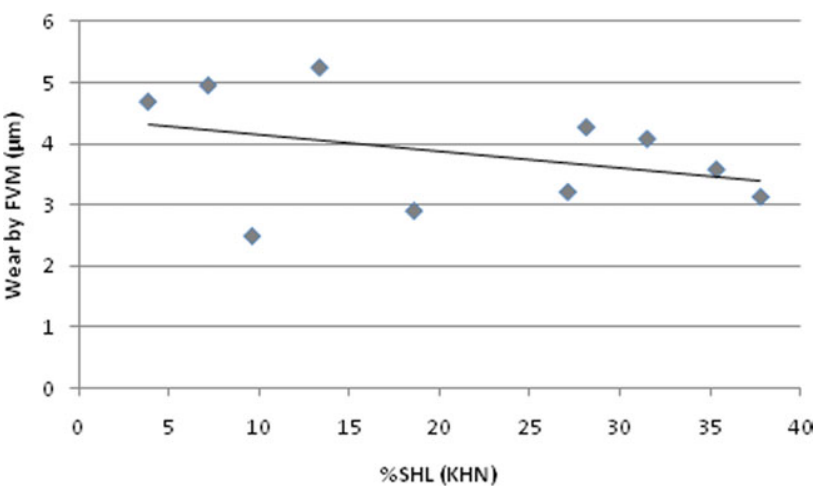

Fig. 2. Correlation between surface wear (FVM) and \%SHL in dentin erosion. [Color figure can be viewed in the online issue, which is available at wileyonlinelibrary.com.]

compared. The Pearson correlation analysis of the dentin surfaces subjected to erosion only showed that $\%$ SHL was inversely correlated with FVM $(r=-0.67$, $P=0.032$ ) (Fig. 2). Differently from enamel, when dentin data were analyzed without considering treatment (erosion/erosion plus abrasion) no significant correlation was determined between the techniques (FVM vs. SHL, $r=0.27$; SHL vs. SP, $r=0.47$ and FVM vs. SP, $r=$ $0.38)$.

Typical surface images with control and treated areas are shown in Figures 3 and 4. In general, all of the test slabs exhibited uniform erosive lesions, which could be easily distinguished from the untreated areas.

\section{DISCUSSION}

This study examined the reproducibility of different methods for analyzing dental erosion with or without abrasion on enamel and dentin. A comparative analysis of two profilometric techniques (one optical and one mechanical) and their correlations with surface hardness was performed.

Focus-variation 3D microscopy has emerged as a leading non-destructive analytical technique in dental hard tissue research (Ren et al., 2009a,b). This new approach presents several advantages: no tissue is lost due to sectioning and three-dimensional rendering and quantification are possible. A proposed benefit of FVM compared with contact stylus is that there is no risk of scratching the eroded, softened enamel surface of the specimen; thus, the true wear of the tooth can be measured (Barbour and Rees, 2004). The selection of the method of measurement is impacted by several issues. The goals of the project determine which outcome measures are required. The study design and the study model are both associated with the method of measurement. In addition, resources (such as expertise), the cost and availability of equipment and time are important considerations. The specifications of a method are also essential, and quantitative or qualitative accuracy should be considered as well (Lo et al., 2010).

According to our results, an erosive challenge followed by an abrasive process on enamel promotes a greater loss of tooth structure than does erosion alone, which is similar to the findings of other studies (Eisenburger and Addy, 2003; Hooper et al., 2003; Rios et al.,
2006). This tendency presumably reflects the removal, by the brushing procedure, of a softened surface made vulnerable to mechanical forces. The results obtained in analysis on enamel substrate show positive correlations with mechanical profilometry and optical profilometry. In contrast, the enamel slabs subjected to erosion alone presented higher percentages of hardness change than those subjected to erosion plus abrasion, indicating an inverse correlation between 3D scanning microscopy analysis and the percentage of surface loss. This result is probably due to the erosion challenge resulting from a direct loss of the superficial enamel layer; in addition, the erosion challenge may have softened the underlying layer, thus resulting in diminished hardness. This softened layer was removed by the brushing procedure, resulting in the exposure of a harder and inner enamel surface (Wiegand et al., 2007). This process caused the wear to increase when the eroded enamel was subjected to abrasion, but the $\%$ SHL was lower compared with that of erosion alone. This hypothesis is supported by previous investigations that have shown that softened enamel is more susceptible to toothbrushing performed immediately after an erosive challenge (Hooper et al., 2003; Rios et al., 2006). The results of the present study also show that abrasion can potentialize the effects of an erosive challenge on enamel.

In contrast, the dentin substrate analysis did not show a significant difference between teeth treated by erosion and those treated by erosion plus abrasion. The interpretation of this result may require some understanding of the complex structure of dentin. The erosive demineralization of dentin causes the exposure of the organic matrix, then the partly demineralized zone and finally the sound inner dentin (Ganss et al., 2001, 2004). Therefore, this demineralized dentin acts as a diffusion barrier; consequently, this layer may assume a buffering capacity sufficient to retard a further demineralization (Ganss et al., 2004). Recently, Ganss et al. (2009) showed that the demineralized organic dentin matrix is strikingly resistant to mechanical impacts, resisting a force of $2 \mathrm{~N}$, which is similar the force applied in our study. Therefore, the similarity between the results of the dentin subjected to erosion alone and that subjected to erosion plus abrasion may be explained by the maintenance of the protective barrier function of the organic portion of the tissue.

Stylus profilometry is widely used to measure enamel and dentin surface loss (Ganss et al., 2009; Turssi et al., 2008). However, a diamond stylus can scratch the dental surface, as shown in this study. That tool's diamond tip has a diameter of $5 \mu \mathrm{m}$. According Ren et al. (2009a), a diamond tip of this diameter may prevent the detection of pits present in an eroded surface that are smaller in diameter than the stylus tip. This limitation is likely responsible for our finding that FVM showed higher wear on enamel and dentin substrates. Therefore, the FVM technique was more sensitive in evaluating wear and showed the true distance between the reference and treated surfaces.

Although measurements with a microscope is a simple, rapid and non-destructive method, it may not be suitable for analyzing enamel with extremely low or 

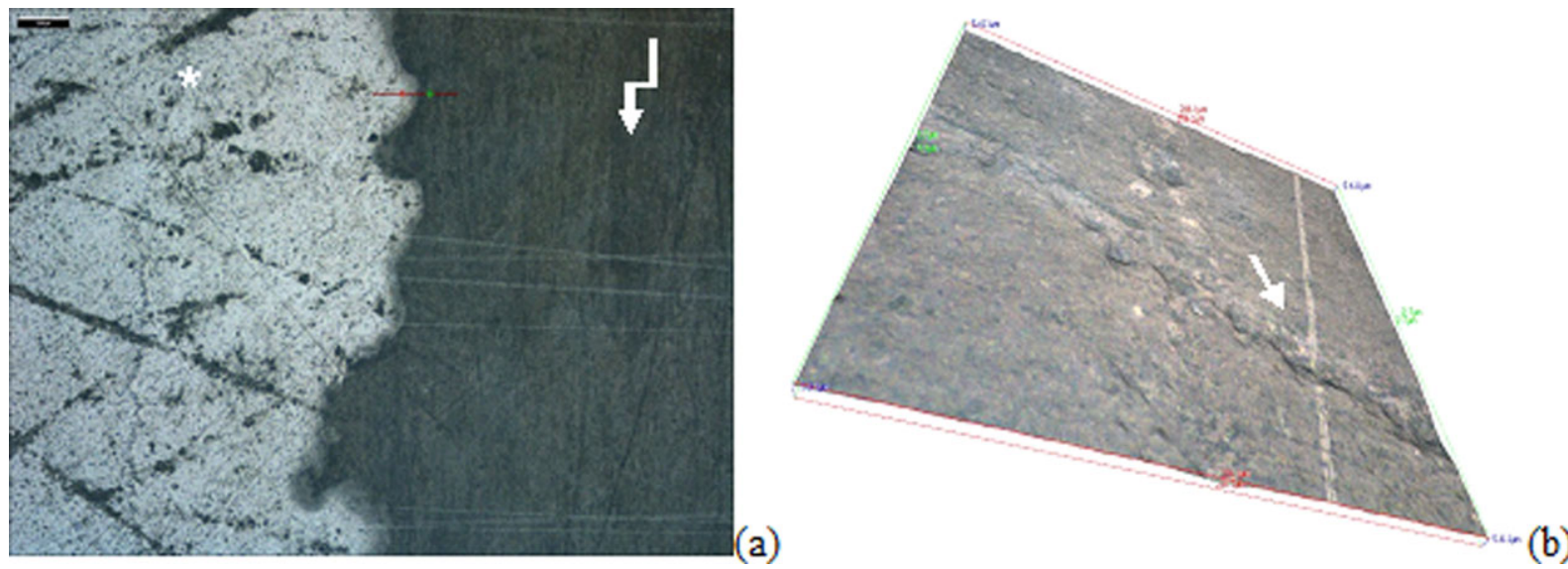

Fig. 3. a: Enamel surface showing both erosive changes (arrow) and the control area (*). b: A 3D topographical image $(200 \times)$ of an eroded tooth sample exhibiting surface scratches created by the profilometry measurements (arrow). [Color figure can be viewed in the online issue, which is available at wileyonlinelibrary.com.]
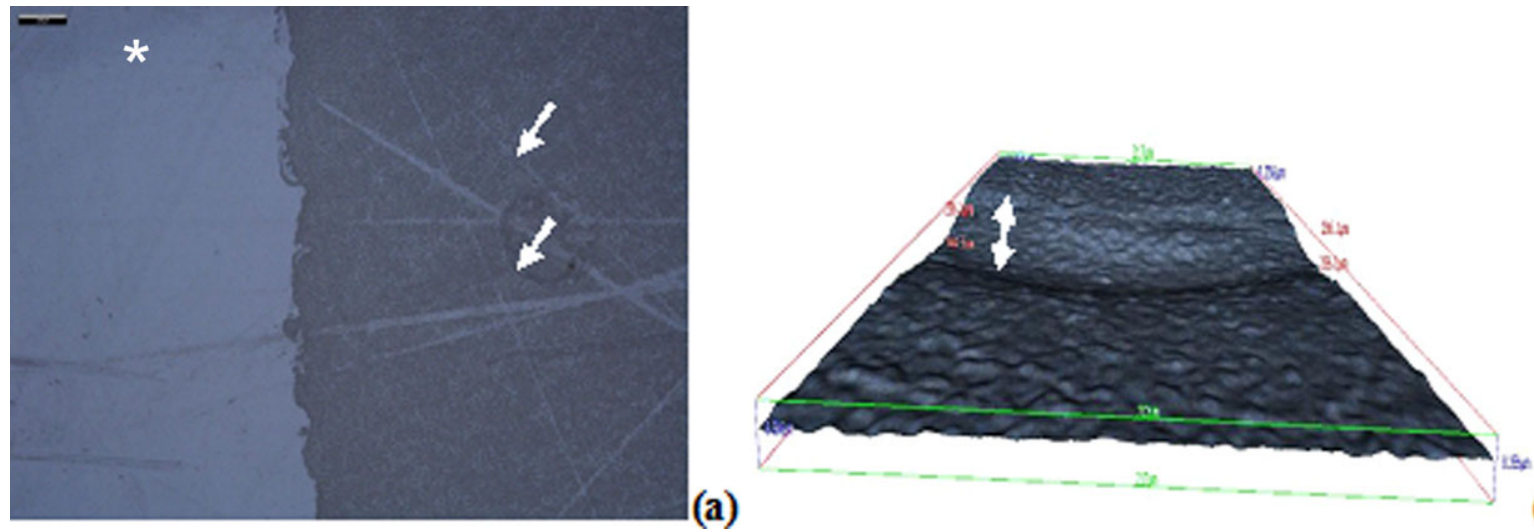

(b)

Fig. 4. a: Dentin surface showing both erosive changes and the control area $(*)$, which exhibited surface scratches created by the profilometry measurements (arrow). b: A 3D topographical image $(200 \times)$ of an image of an eroded dentin sample. The height of this step represents the amount of dentin loss. [Color figure can be viewed in the online issue, which is available at wileyonlinelibrary.com.]

early erosion because the measurement accuracy can be influenced by focusing the objective lens (Chuenarrom and Benjakul, 2008; Zheng et al., 2009). Therefore, profilometry is not the ideal method to measure the small changes that occur in the initial stages of erosion (Hara and Zero, 2008; Hjortsjo et al., 2010).

According to ours results, when a less aggressive process is performed on dentin, a better choice to examine the substrate alteration is FVM, which provides 3D measurements that give a more accurate assessment than others techniques (Rodriguez and Bartlett, 2010). Some of the differences between the results obtained using different surface methodologies, especially those between contact and non-contact methods, may be explained by noting that the results of optical measurements are influenced not only by purely geometrical changes in the surface (Heurich et al., 2010) but also by chemical changes induced by processing that might influence the local index of refraction of the surface.
Caution should be exercised when comparing the results of studies of surface eroded/abraded dental hard tissues using varying types of measurement methods. Collectively, these results suggest that SHL analysis is a sensitive method for detecting the small changes that occur in enamel without tissue loss. When the acid challenge is higher, a profilometric analysis may be proposed. The results of the present work indicate that both SP and FVM are sensitive in detecting changes in the mineral density of artificial eroded/ abraded lesions in an enamel substrate. However, in dentin, the FVM technique was more sensitive in detecting structural changes following erosive and abrasive processes.

\section{ACKNOWLEDGMENTS}

The first and second authors thank CNPq for concession of scholarships during this study (Proc. \#140643/ 2011-7 and \#141791/2010-1, respectively). 


\section{REFERENCES}

Attin T. 2006. Methods for assessment of dental erosion. Monogr Oral Sci 20:152-172.

Barbour ME, Rees JS. 2004. The laboratory assessment of enamel erosion: A review. J Dent 32:591-602.

Chuenarrom C, Benjakul P. 2008. Comparison between a profilometer and a measuring microscope for measurement of enamel erosion. J Oral Sci 50:475-479.

de Carvalho Filho AC, Sanches RP, Martin AA, Do Espírito Santo AM, Soares LE. 2011. Energy dispersive X-ray spectrometry study of the protective effects of fluoride varnish and gel on enamel erosion. Microsc Res Tech 74:839-844.

Eisenburger M, Addy M. 2003. Influence of liquid temperature and flow rate on enamel erosion and surface softening. J Oral Rehab 30:1076-1080.

Field J, Waterhouse P, German M. 2010. Quantifying and qualifying surface changes on dental hard tissues in vitro. J Dent 38:182190.

Fujii M, Kitasako Y, Sadr A, Tagami J. 2011. Roughness and pH changes of enamel surface induced by soft drinks in vitro applications of stylus profilometry, focus variation 3D scanning microscopy and micro pH sensor. Dent Mater J 30:404-410.

Ganss C, Klimek J, Schäffer U, Spall T. 2001. Effectiveness of two fluoridation measures on erosion progression in human enamel and dentine in vitro. Caries Res 35:325-330.

Ganss C, Klimek J, Schwarz N. 2000. A comparative profilometric in vitro study of the susceptibility of polished and natural human enamel and dentine surfaces to erosive demineralization. Arch Oral Biol 45:897-902.

Ganss C, Klimek J, Starck C. 2004. Quantitative analysis of the impact of the organic matrix on the fluoride effect on erosion progression in human dentine using longitudinal microradiography. Arch Oral Biol 49:931-935.

Ganss C, Lussi A, Klimek J. 2005. Comparison of calcium/phosphorus analysis, longitudinal microradiography and profilometry for the quantitative assessment of erosive demineralisation. Caries Res 39:178-184.

Ganss C, Lussi A, Scharmann I, Weigelt T, Hardt M, Klimek J, Schlueter N. 2009. Comparison of calcium analysis, longitudinal microradiography and profilometry for the quantitative assessment of erosion in dentine. Caries Res 43:422-429.

Hannig C, Becker K, Yankeu-Ngalene VE, Attin T. 2008. Applicability of common methods for short time erosion analysis in vitro. Oral Health Prev Dent 3:239-248.

Hara AT, Zero DT. 2008. Analysis of the erosive potential of calcium-containing acidic beverages. Eur J Oral Sci 116:60-65.

Heurich E, Beyer M, Jandt KD, Reichert J, Herold V, Schnabelrauch M, Sigusch BW. 2010. Quantification of dental erosion - A comparison of stylus profilometry and confocal laser scanning microscopy (CLSM). Dent Mater 26:326-336.
Hjortsjo C, Jonskib G, Young A, Saxegaard E. 2010. Effect of acidic fluoride treatments on early enamel erosion lesions - A comparison of calcium and profilometric analyses. Arch Oral Biol 55:229-234.

Hooper S, West NX, Pickles MJ, Joiner A, Newcombe RG, Addy M. 2003. Investigation of erosion and abrasion on enamel and dentine: A model in situ using toothpastes of different abrasivity. J Clin Periodontol 30:802-808.

Lo EC, Zhi QH, Itthagarun A. 2010. Comparing two quantitative methods for studying remineralization of artificial caries. J Dent 38:352-359.

Lussi A, Kohler N, Zero D, Schaffner M, Megert B. 2000. A comparison of the erosive potential of different beverages in primary and permanent teeth using an in vitro model. Eur J Oral Sci 108:110-114.

Passos VF, Santiago SL, Tenuta LMA, Cury JA. 2010. Protective effect of NaF/triclosan/copolymer and MFP dentifrice on enamel erosion. Am J Dent 23:193-195.

Ren YF, Amin A, Malmstrom H. 2009b. Effects of tooth whitening and orange juice on surface properties of dental enamel. J Dent 37:424-431.

Ren YF, Zhao Q, Malmstrom H, Barnes V, Xu T. 2009a. Assessing fluoride treatment and resistance of dental enamel to soft drink erosion in vitro: Applications of focus variation 3D scanning microscopy and stylus profilometry. J Dent 37:167-176.

Rios D, Honório HM, Magalhães AC, Buzalaf MA, Palma-Dibb RG, Machado MA, da Silva SM. 2006. Influence of toothbrushing on enamel softening and abrasive wear of eroded bovine enamel: An in situ study. Braz Oral Res 20:148-54.

Rodriguez JM, Bartlett DW. 2010. A comparison of two-dimensional and three-dimensional measurements of wear in a laboratory investigation. Dent Mater 26:221-225.

Saghiri MA, Delvarani A, Mehrvarzfar P, Malganji G, Lotfi M, Dadresanfar B, Saghiri AM, Dadvand S. 2009. A study of the relation between erosion and microhardness of root canal dentin. Oral Surg Oral Med Oral Pathol Oral Radiol Endod 108:29-34.

Schlueter N, Klimek J, Ganss C. 2009a. Efficacy of an experimental tin-F-containing solution in erosive tissue loss in enamel and dentine in situ. Caries Res 43:415-421.

Schlueter N, Klimek J, Ganss C. 2009b. In vitro efficacy of experimental tin- and fluoride-containing mouth rinses as anti-erosive agents in enamel. J Dent 37:944-948.

Serra MC, Messias DC, Turssi CP. 2009. Control of erosive tooth wear: Possibilities and rationale. Braz Oral Res 23:49-55.

Turssi CP, Hara AT, Domiciano SJ, Serra MC. 2008. Study on the potential inhibition of root dentine wear adjacent to fluoride-containing restorations. J Mater Sci: Mater Med 19:47-51.

Wiegand A, Köwing L, Attin T. 2007. Impact of brushing force on abrasion of acid-softened and sound enamel. Arch Oral Biol 52:1043-1047.

Zheng J, Xiao F, Qian LM, Zhou ZR. 2009. Erosion behavior of human tooth enamel in citric acid solution. Trib Intl 42:1558-1564. 